\title{
The Evaluation of the Children with Renal Transplant: Single Centre Experience
}

\begin{tabular}{|c|c|}
\hline Author(s) & 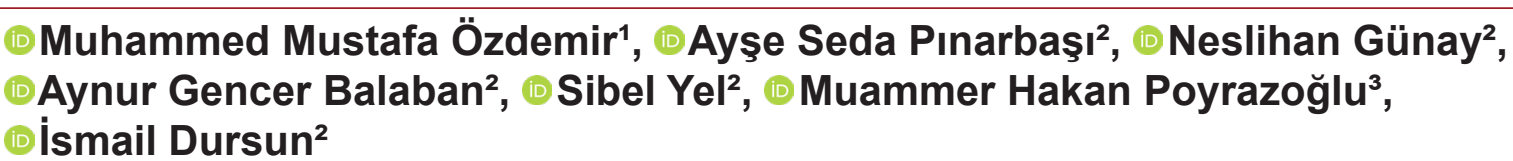 \\
\hline Affiliation(s) & $\begin{array}{l}{ }^{1} \text { Health Ministry, Ciftlik State Hospital, Nigde, Turkey } \\
\text { 2Department of Pediatric Nephrology, Erciyes University, Faculty of Medicine, Kayseri, Turkey } \\
\text { 'Department of Pediatric Nephrology-Rheumatology, Erciyes University, Faculty of Medicine, Kayseri, Turkey }\end{array}$ \\
\hline $\begin{array}{c}\text { Article } \\
\text { Information }\end{array}$ & $\begin{array}{l}\text { Received: } 16.10 .2020 \\
\text { Accepted: } 18.11 .2020 \\
\text { Available Online: } 27.12 .2020\end{array}$ \\
\hline
\end{tabular}

\section{Abstract}

This study aimed to evaluate patients with renal transplantation in terms of clinical and laboratory parameters. This study was performed retrospectively with records of 48 patients who underwent renal transplantation before 18 years of age, between June 2008 and July 2019.Congenital malformations of the urinary tract were the most common underlying causes of chronic kidney disease stage 5. Surgical complications occurred in $33.4 \%$ of the patients and BK viremia was the most common opportunistic viral infection during the follow-up. At the last clinic visit, $57.4 \%$ of our patients had CKD stage 1 , hypertension and nephrotic range proteinuria were seen in eight and two patients, respectively.Although renal transplantation is the most ideal renal replacement therapy, patients may experience various complications during the follow-up. Therefore, they should be monitored regularly.

Keywords: Chronic kidney disease stage 5, kidney transplantation

\section{Introduction}

Although kidney transplantation is the most ideal treatment for adults and children who have reached the chronic kidney disease stage 5 (CKD5), long-term deterioration in graft functions may occur due to primary disease, surgical complications, rejection, and side effects of the immunosuppressive drugs. Although new surgical methods and medical treatments significantly improve graft survival and patient quality of life, some complications can be seen during

the follow-up. ${ }^{1}$ The surgical and urological complications, such as ureteral obstruction or urinary leakage, may result in morbidity and graft loss at the early period of transplantation. ${ }^{2}$ Infections and rejection may deteriorate allograft functions during the course of transplant follow-up. In this retrospective study, we aimed to evaluate the patients with renal transplantation in terms of clinical and laboratory parameters. 


\section{Material and Method}

We retrospectively reviewed the medical records of 53 children with kidney transplant who underwent kidney transplantation before the age of 18 and were followed up between June 2008 and July 2019 in the department of Pediatric Nephrology. Approval was obtained from the Local Ethics Committee on 09.05.2018/255

Medical records were reviewed for clinical data including gender, age, anthropometric measurements, underlying cause of CKD5, dialysis modality before transplantation, surgical complications during and after transplantation, induction and maintenance therapies, post-transplant medical problems (hypertension, proteinuria, infection, rejection, chronic kidney disease, etc.) and continuation of clean intermittent catheterization after transplant

The Schwartz formula was used for the calculation of estimated GFR (eGFR). The constant k was defined based on literature values: $k=0.55$ for children aged 2-12 or adolescent females and $k=0.7$ for adolescent males. ${ }^{3}$

The measurement of CMV, EBV and BKV viral loads were done using by a polymerase chain reaction (PCR). The measured value above $250 \mathrm{IU}$ / $\mathrm{mL}$ was accepted as CMV viremia. ${ }^{4}$ EBV and BK were accepted as viremia criteria according to the virology laboratory values of Erciyes University Hospital. The value above 26 copy/mL and 316 copy/mL was accepted as $B K$ and EBV viremia, respectively.

Five patients were excluded from study because of lack of data and analysis was completed with 48 patients.

\section{Statistical Analysis}

SPSS Windows software was used for the statistical analysis. Whether the quantitative variables showed normal distribution was tested with the Shapiro Wilk normality test. Descriptive statistics were shown as mean \pm standard deviation for variables with normal distribution, as median (min-max) for variables with non-normal distribution, and several cases and (\%) for nominal variables.

When the number of groups was two, the significance of the difference between the groups in terms of means was investigated with the t-test and the Mann Whitney-U test. Nominal variables were evaluated using Pearson Chi-Square or Fisher's exact test. A P-value of less than 0.05 was considered statistically significant.

\section{Results}

In our study, the patient group consisted of 30 boys and 18 girls (ratio 1.7:1). Peritoneal dialysis was used as renal replacement therapy in $18(72 \%)$. The mean age at the time of transplantation was 9.8 years and follow-up duration was $55,8 \pm 33,5$ months. The duration of graft survival was $56,3 \pm 34,2$ months. Kidney transplantation was performed from living donors in 38 patients $(79.2 \%)$ and cadaver in 10 patients (20.8\%). Preemptive kidney transplant was done in 23 patients (47.9\%). The leading resource in living donors was the mother with $65 \%$. Congenital Malformations of the Kidney and Urinary Tract (CAKUT) is the most common cause of CKD5 (50 \%), followed by glomerulonephritis (14.6\%).

Graft loss was seen in four patients $(8.3 \%)$. Two of them died during the follow-up, one from vascular thrombosis and another one from invasiveaspergillusinfection possibly due to treatment with intensive immunosuppressive therapy for the rejection. One patient had chronic allograft nephropathy and one patient had BK nephropathy.

Surgical complications developed in $33.4 \%$ of the patients ( $n: 16)$ and the most common surgical complication was found to be UV stenosis. In $87.5 \%$ (n: 14) of the patients who developed surgical complications, the complication was also surgically corrected.

While proteinuria was present in $6(75 \%)$ of 8 patients with hypertension at the last control, proteinuria was detected in $23.5 \%$ of patients without hypertension. The difference between these two groups was statistically significant $(p<0.05)$.

When the CKD staging at the last control was compared with proteinuria and hypertension, it was found that our patient, who was at stage 5 , had both proteinuria and hypertension. The difference between CKD staging and hypertension at the last control was statistically significant $(p<0.05)$ (Table 1).

Urinary tract infection was the most common infection seen in renal transplant recipients $(62.5 \%) .18(37.5 \%)$ of the patients had at least 2 or more urinary tract infections during their post-transplant follow-up. Besides, 10 patients experienced with pneumonia at follow-up. Patients' induction treatments and $\mathrm{CMV}$, EBV, and BK viremia were compared, and a statistically significant difference was found between CMV viremia and induction therapies (Table 2). CMV viremia was more common in patients who used ATG than those patients who used Basiliximab

\begin{tabular}{|c|c|c|c|c|c|c|}
\hline & & \multicolumn{5}{|c|}{ CKD Stage } \\
\hline & & Stage 1 & Stage 2 & Stage 3 & Stage 5 & P Value \\
\hline \multirow{3}{*}{ Proteinuria } & Nephrotic range & 1 & 1 & 0 & 0 & \multirow{3}{*}{0.256} \\
\hline & Non- nephrotic range & 9 & 1 & 1 & 2 & \\
\hline & No & 17 & 8 & 4 & 0 & \\
\hline \multirow{2}{*}{ Hypertension } & Yes & 5 & 1 & 0 & 2 & \multirow{2}{*}{0.018} \\
\hline & No & 21 & 8 & 5 & 0 & \\
\hline
\end{tabular}




\begin{tabular}{|c|c|c|c|c|c|}
\hline & & ATG & Basiliximab & Total & P Value \\
\hline \multirow{2}{*}{ CMV Viremia } & Yes & 6 & 9 & 15 & \multirow{2}{*}{0.05} \\
\hline & No & 4 & 29 & 33 & \\
\hline \multirow{2}{*}{ EBV Viremia } & Yes & 5 & 8 & 13 & \multirow{2}{*}{0.108} \\
\hline & No & 5 & 30 & 35 & \\
\hline \multirow{2}{*}{ BK Viremia } & Yes & 2 & 11 & 13 & \multirow{2}{*}{0.706} \\
\hline & No & 8 & 27 & 35 & \\
\hline
\end{tabular}

\section{Discussion}

Persistent proteinuria and hypertension are the risk factors for the progression of CKD and poor graft survival in transplanted patients. ${ }^{5}$ In our study, the most of the patients with hypertension had proteinuria at last followup and patients having both hypertension and proteinuria had poor graft function.

Acute rejection attacks are an important factor affecting long-term kidney survival. ${ }^{6}$ Considering the development of acute rejection and the last GFR of the patients in our study, it was found that the patients who had rejection had lower GFR. In our study, it was observed that only one of the seven patients who had stage III-V according to the CKD staging at the last follow-up did not experience acute rejection and the other six patients had rejection. In a study performed in Mexico, it was found that acute rejection was a negative predictor of graft survival, as seen in our study. ${ }^{7}$

Infections are an important complication that results in recurrent hospitalizations and poor graft survival in kidney transplant patients. ${ }^{8}$ In our study, it was determined that $62.5 \%$ of the patients with kidney transplantation had at least one infection during their follow-up. Pourmand et al. ${ }^{8}$ found that $54.2 \%$ of the patients had an infection attack at least once during a one-year follow-up. In our study, it was determined that the most common infection was urinary system infection, followed by BK viremia. In our study, the rate of urinary tract infection in the first year was found to be $37.5 \%$. This rate is between 35 and $80 \%$ in the literature, and is similar to our study. ${ }^{8}$ As previously shown in adult transplant recipients, urinary tract infections did not increase the risk of rejection. ${ }^{9}$ However, urinary tract infections, transplantation procedures, prevention of rejection development and immunosuppression treatments used in rejection have been found to increase the risk of infection. ${ }^{10}$ Recurrent urinary tract infections were found in four of our patients in our study. Recurrent urinary tract infection of three of these patients started after the first year and two of them had GFR rates above stage III according to the CKD staging in the third year in their follow-up. None of these patients experienced graft loss.

In the literature, the frequency of $\mathrm{BK}$ viremia varies between $15.4 \%$ and $39.7 \% .{ }^{11,12}$ It was seen $33.3 \%$ of patients in our study. Although there was no significant relationship between BK viremia and graft survival, BK viremia may cause nephropathy and graft loss in the transplanted kidney in the literature. ${ }^{12}$ One patient in our cohort experienced with BK virus nephropathy at $4^{\text {th }}$ months of transplant. We switched MMF with leflunomide and decreased target level of tacrolimus, and additionally gave him cidefovir and IVIG. He did not give response to management and reached at CKD5 at $12^{\text {th }}$ months of transplant.

The induction regimen may increase susceptibility to infections in kidney transplant patients. Luan et al. ${ }^{13}$ evaluated the impact of various antibody induction regimens on CMV infection in adult kidney and/or pancreas transplant patients. They showed that the use of rATG but not basiliximab was found to be associated with an increased risk for CMV infection. In another study, Bayraktar et al. ${ }^{14}$ investigated the role of induction therapy on the onset of CMV disease in 257 adult kidney transplant patients and showed that a higher dosage of ATG was associated with an increased risk of CMV disease. In line with these, the use of ATG as induction therapy resulted in increased number of CMV infection in our study. Although EBV infection is less common than $\mathrm{CMV}$ or BK virus infection, it may negatively affect graft survival in solid organ transplants, if it is complicated with post-transplant lymphoproliferative disease (PTLH) which is a potentially fatal complication after transplantation. ${ }^{15,16}$ The incidence of EBV infection ranges from 30 to $44 \%$ in pediatric transplant patients. ${ }^{17,18}$ You et al. ${ }^{17}$ monitored pediatric kidney transplant patients in term of EBV infection and PTLD. They demonstrated that 21 patients of 70 renal transplant recipients had EBV infection and six of them developed PTLD and the mortality rate in those patients was $16.6 \%$. In our study, PTLH developed in 1 of 9 patients with EBV infection at the 6th year of kidney transplantation. His immunosuppression was decreased and rituximab based chemotherapy was given. With this, PTLD resolved without any rejection.

\section{Conclusion}

Kidney transplantation is an important chronic disease that can cause morbidity and mortality despite the all development treatment strategy. Especially, patients should be closely monitored for opportunistic infections and PTLD.

Acknowledgements: This study was accepted as a oral poster the 6th Anniversary Meeting of the EPA, February 27-29 2019, Kayseri

Author Contributions: All of the authors declare that they have all participated in the design, execution, and analysis of the paper, and that they have approved the final version 
Conflict of Interest: All the authors declare that they have not received any financial support or other benefits from commercial sources for the work described in this paper. They also declare that they have no other financial interests that could create a potential conflict of interest or the appearance of a conflict of interest with regard to this work.

Ethics Committee Approval: Local ethics committee was approved this study with the number of 09.05.2018255.

Financial Disclosure: The authors declared that this study has received no financial support.

Informed Consent: Written Informed consent was obtained from all individual participants included in the study.

Peer-review: Externally peer-reviewed.

\section{References}

1. Erbas B. Peri- and Postsurgical Evaluations of Renal Transplant. Semin Nucl Med 2017;47:647-659. [CrossRef]

2. Dinckan A, Tekin A, Turkyilmaz $S$ et al. Early and late urological complications corrected surgically following renal transplantation. Transpl Int. 2007;20:702-707. [CrossRef]

3. Bek K, Akman S, Bilge I et al. Chronic kidney disease in children in Turkey. Pediatr Nephrol. 2009;24:797-806. [CrossRef]

4. Jorgenson MR, Descourouez JL, Saddler CM. Post Kidney Transplant: Infectious Complication. In: Parajuli S, Aziz F, eds. Kidney Transplantation Management - A Guide to Evaluation and Comorbidities,1st ed. Switzerland: Springer, 2019:73-93.

5. Diena D, Messina M, De Biase C, et al. Relationship between early proteinuria and long term outcome of kidney transplanted patients from different decades of donor age. BMC Nephrol. 2019;20:443458. [CrossRef]

6. Martinez-Mier G, Mendez-Lopez MT, Soto-Miranda E, et al Acute Rejection Is a Strong Negative Predictor of Graft Survival in Living-Donor Pediatric Renal Transplant: 10-Year Follow-Up in a Single Mexican Center. Exp Clin Transplant. 2019;17:170-176. [CrossRef]
7. Basiratnia M, Esteghamati M, Ajami GH et al. Blood pressure profile in renal transplant recipients and its relation to diastolic function: tissue Doppler echocardiographic study. Pediatr Nephrol. 2011;26:449-457. [CrossRef]

8. Opelz G, Döhler B; Collaborative Transplant Study Report. Influence of time of rejection on long-term graft survival in renal transplantation. Transplantation. 2008;85:661-666. [CrossRef]

9. Giral M, Pascuariello G, Karam G et al. Acute graft pyelonephritis and long-term kidney allograft outcome. Kidney Int. 2002;61:18801886. [CrossRef]

10. Audard V, Amor M, Desvaux D et al. Acute graft pyelonephritis: a potential cause of acute rejection in renal transplant. Transplantation. 2005;80:1128-1130. [CrossRef]

11. Pourmand G, Salem S, Mehrsai A et al. Infectious complications after kidney transplantation: a single-center experience. Transpl Infect Dis. 2007;9:302-309. [CrossRef]

12. SchwarzA, Linnenweber-Held S, Heim A et al.. Viral Origin, Clinical Course, and Renal Outcomes in Patients With BK Virus Infection After Living-Donor Renal Transplantation. Transplantation. 2016;100:844-853. [CrossRef]

13. Luan FL, Samaniego M, Kommareddi M, Park JM, Ojo AO. Choice of induction regimens on the risk of cytomegalovirus infection in donor-positive and recipient-negative kidney transplant recipients. Transpl Infect Dis. 2010;12:473-479. [CrossRef]

14. Bayraktar A, Catma Y, Akyildiz A et al. Infectious Complications of Induction Therapies in Kidney Transplantation. Ann Transplant. 2019;24:412-417. [CrossRef]

15. Mohamed Maha. Kidney Transplant: Malignancies. In: Parajuli S, Aziz F, eds. Kidney Transplantation Management - A Guide to Evaluation and Comorbidities,1st ed. Switzerland: Springer, 2019: 95-101.

16. Nijland ML, Kersten MJ, Pals ST, Bemelman FJ, Ten Berge IJ. Epstein-Barr Virus-Positive Posttransplant Lymphoproliferative Disease After Solid Organ Transplantation: Pathogenesis, Clinical Manifestations, Diagnosis, and Management. Transplant Direct. 2015;2:e48. [CrossRef]

17. You J, Kim M, Lee J, Han DJ, Park YS, Lee JH. Epstein-Barr virus infection in children with renal transplantation: A singlecentre experience. Nephrology (Carlton). 2018;23:1039-1045. [CrossRef]

18. Shroff R, Trompeter R, Cubitt D, Thaker U, Rees L. Epstein-Barr virus monitoring in paediatric renal transplant recipients. Pediatr. Nephrol. 2002;17:770-775. [CrossRef] 